\title{
A rede de fast-food KFC e o hábito de consumir frango frito no balde
}

no Brasil: uma proposta de periodização

\author{
KFC fast-food chain and the consumption habit offried chicken bucket \\ in Brazil: a periodization proposal
}

\section{Marina Araújo' \\ Fábio Tozi}

RESUMO: A proposta do artigo é refletir sobre a implantação da rede estadunidense de fastfood Kentucky Fried Chicken (KFC), especializada na venda de cortes de frango frito em baldes, no Brasil e, particularmente, em Belo Horizonte (MG). Propõe-se uma periodização das três tentativas da empresa em instalar-se no país, com destaque para a difusão e as resistências ao consumo de "frango frito no balde". A proposta incorpora o desenvolvimento de redes concorrentes nacionais ou estabelecimentos locais que mimetizam o conceito da KFC, muitas vezes antecedendo-se à chegada dela - isto é, o hábito de comer frango frito no balde instalou-se antes da própria rede que o criou e difundiu. Além disso, observa-se na capital mineira relevante número de pequenos restaurantes locais especializados na venda de frango frito no balde, adaptando o conceito original a partir das suas limitações financeiras, técnicas e organizacionais. Finalmente, acredita-se que esses restaurantes criaram uma expressiva heterogeneidade de formas e fluxos no território belo-horizontino, revelando, empiricamente, tanto a difusão de um hábito alimentar que se globaliza quanto formas de adaptação que nomeamos de "flexibilidade tropical" (SANTOS, 1996).

Palavras-chave: KFC; flexibilidade tropical; globalização do gosto; fast-food; hábitos alimentares.

\footnotetext{
${ }^{1}$ Bacharel em Turismo, graduanda em Geografia na Universidade Federal de Minas Gerais (UFMG). Contato: marinaaraujo84@gmail.com.

${ }^{2}$ Professor do Departamento de Geografia da Universidade Federal de Minas Gerais, Doutor em Geografia pela Universidade de São Paulo (USP). Contato: fabio.tozi@gmail.com.
} 
ABSTRACT: This article's proposal is to dwell on the implementation of the Kentucky Fried Chicken (KFC) American fast-food chain, specialized in fried chicken buckets, in Belo Horizonte (MG). It aims to a "periodization" of the company's three attempts at settling itself in the country, emphasizing the diffusion and resistances of fried chicken bucket consumption. The proposal incorporates the development of national competitor chains or local establishments which mirror the KFC concept, many times preceding its appearance that is, the habit of eating fried chicken bucket may have settled before the own chain which created it and spread it. Besides that, it is noted in the capital of Minas Gerais, a relevant number of small local restaurants specialized in fried chicken bucket, adapting its original concept before their financial, technical and organizational limitations. Finally, it is believed that these restaurants created an expressive heterogeneity of forms and flows in Belo Horizonte's territory, empirically revealing not only the spread of a globalizing eating habit but also forms of adaptation that we name "tropical flexibility" (SANTOS, 1996).

Keywords: KFC; tropical flexibility; taste globalization; fast-food; eating habits.

Recebido em 16 de março de 2020; aprovado em 08 de junho 2020.

\section{Alimentação e consumo: o fast-food como suporte da globalização de hábitos alimentares e a persistência das adaptações "lugarizadas"}

Os hábitos alimentares são práticas culturais que carregam consigo diversas histórias. Concorda-se com Certeau (2000 [1990]), quando afirma que o ato de se alimentar reveste-se de uma "montagem sutil de gestos, de ritos e de códigos, de ritmos e de opções, de hábitos herdados e de costumes repetidos" (CERTEAU, 2000 [1990], p. 234). Assim, o ato de comer engloba as relações pessoais, sociais e culturais nele envolvidas.

Neste sentido, todos precisam comer, mas não o fazem da mesma maneira. Segundo Morel et al. (2016, p. 182), "estando os indivíduos inseridos em contextos sociais específicos com hábitos e crenças particulares - a comida e o comer passam a ser modelados pela cultura 
à medida que a alimentação se configura como aprendizado sociocultural e historicamente derivado do ambiente em que se está inserido". Sendo assim, os regimes alimentares de cada sociedade revelam uma ordem de mundo própria (CERTEAU, 2000 [1990]), por isso eles são diferentes em cada lugar.

No entanto, a partir da difusão da informação e do fluxo de pessoas pelo mundo, as trocas culturais se acentuam e provocam, ao mesmo tempo, conservadorismos e mudanças nos comportamentos alimentares.

Neste novo cenário, novos hábitos alimentares vindos de outras localidades dividem espaço com hábitos historicamente perpetuados, em um movimento de coexistência entre o novo e o antigo, sugerindo que as identidades alimentares podem ser criadas e desfeitas ao longo do tempo. (MOREL et al., 2016, p. 183)

Ressalta-se, desta forma, o importante papel desempenhado pela informação, em sua fluida circulação pelo globo, na formação de novos hábitos alimentares e novos consumidores. Nas palavras de Certeau (2000 [1990], p. 339), "a comunicação é uma cozinha de gestos e de palavras, de ideias e de informações, com suas receitas e suas sutilidades, seus instrumentos auxiliares e seus efeitos de vizinhança, suas distorções e seus malogros". Outros autores, como Fischler (2015 [1996]), discorrem acerca de uma "McDonaldização" dos costumes alimentares, enquanto Fumey e Raffard (2018) propõem pensar em uma "Revolução Food 2.0", aliando novos agentes, como startups, à biotecnologia e à indústria da alimentação herdada do século XX.

Assim, por meio da informação e das estratégias dos grandes agentes corporativos, certa cultura alimentar urbana se massifica, induzindo adequações ao que e como comer. Existiria, então, para além das históricas trocas culturais sustentadas pelo alimentar-se, um poder manipulador de hábitos que refletem interesses comerciais. Concretamente, como observa Leonardo (2009), há o exercício de um poder absoluto quando ocorre a indução e a coerção à aquisição de um produto alimentício específico. Um exemplo concreto desse processo é a difusão de fast-foods por todo o mundo, manifestando a face alimentar hegemonizante do processo de globalização da economia.

Característicos da cultura alimentar estadunidense, os fast-foods provocaram transformações na comensalidade de diversas sociedades. Apoiam-se no desenvolvimento, em meados do século passado, de novos processos organizacionais de trabalho, incluindo 
desde o preparo à venda dos alimentos, aliados ao desenvolvimento tecnológico do setor, à capitalização crescente e ao uso de informações estratégicas por meio de consultorias e sondagens de mercado e de hábitos alimentares. Se, como adverte Leonardo (2009), a quebra de um hábito se dá por meio da evolução nas informações transmitidas para que as pessoas tomem uma decisão, faz-se mister refletir sobre o papel central da informação nas "sociedades burocráticas de consumo dirigido", conforme a célebre definição de Lefebvre (1969 [1968]).

Nesse sentido, é possível afirmar que o período contemporâneo se distingue sobremaneira dos antecedentes por sua capacidade de revolucionar os modos de vida antes existentes. Informação e consumo, duas variáveis elaboradas no centro do sistema capitalista, têm obtido uma difusão rápida e generalizada nos países periféricos, transformando a economia, a sociedade e a organização do espaço, como bem observa Santos (1979). Concorda-se com o autor quando afirma que a informação está a serviço do consumo nos países pobres e que, juntas, por meio de suas diferentes repercussões, são capazes de gerar forças de concentração e de dispersão no espaço geográfico.

Como seu oposto-complementar, as resistências e adaptações locais adquirem relevância diante das formas de dominação que caracterizam a Ocidentalização do mundo, entendida como a conformação dos lugares a funções necessárias à preservação eficiente dos fluxos da rede mundial de cidades e do mercado global (RIBEIRO, 2004): "este fenômeno, que conjuga economia e pretensões civilizatórias, pressiona o próprio Ocidente, racionalizando os usos do espaço historicamente construído e criando redes especializadas, e usualmente excludentes, de cooperação entre operadores da ordem tecnocultural" (RIBEIRO, 2013, p.19).

Desse modo, a partir desta relação dialética entre a Ocidentalização do mundo e as resistências dos lugares, é possível pensar no conceito de Oriente negado, igualmente proposto por Ribeiro (2013), que corresponde tanto às áreas ainda não atingidas por esta ordem tecnocultural, como à força dos espaços e da sociedade, em sua resistência, frente às exclusões determinadas pelo agir hegemônico. A autora busca chamar a atenção para o fato de que o Brasil não é um país totalmente Ocidental, mas em processo de Ocidentalização. Dessa maneira, formas modernas convivem com as tradicionais, formando um campo fértil para a análise das mudanças socioespaciais. Em consequência, a aceitação de atividades 
modernas ou a permanência de atividades não modernas depende da resistência ou da abertura da população dos países pobres aos consumos modernos (SANTOS, 1979).

Traduzindo esse debate para a proposta da nossa pesquisa, temos que a expansão das redes de alimentação rápida estadunidenses no Brasil, e, particularmente a da rede de "frango frito no balde" KFC (Kentucky Fried Chicken), seria uma manifestação empírica desse processo de Ocidentalização. O Oriente negado, por sua vez, diria respeito tanto à desvalorização social das formas tradicionais ou não modernas, quanto às formas de adaptação das formas modernas a partir dos gostos e hábitos ancestrais e "lugarizados", sem excluir os contingenciamentos objetivos da limitação da renda nas grandes cidades brasileiras. Ora, basta percorrer cidades do país para apreender a diversidade de formas de alimentação popular de baixo custo que persistem, ainda que suscetíveis a processos de gourmetização: o PF (Prato Feito), o X-Tudo, pastéis, coxinhas, caldo de cana, "pingado", pãona-chapa, marmitas, sucarias, sanduicherias, lojas de frutas, doces ou açaí.

No entanto, são inegáveis a existência e a influência das forças da informação na difusão de novos modelos de consumo inspirados nos países centrais: a presença ou o simples conhecimento da existência de novos bens e novos métodos de consumo aumentam a propensão geral a certos consumos, fenômeno que é definido por Santos (1979) como "efeitodemonstração internacional". Uma das materializações desse efeito-demonstração nos países pobres é o fast-food, uma forma de consumo que introduziu no cotidiano, sobretudo a partir das grandes cidades, práticas sociais produtoras de espaço, inicialmente pelas classes mais altas e médias para depois se popularizar.

O fast-food americano, afirma Ortigoza (2008), possui uma imagem globalizada que se torna uma mercadoria do consumo: o local onde se consome a refeição rápida é também valorizado pelo seu conteúdo subjetivo, ou seja, pelo modo de vida normatizado que ele proporciona e pela sensação de pertencer, mesmo que momentaneamente, àquele mundo "moderno" concebido nos centros externos desse processo. Da escassez objetiva de tempo nas metrópoles a uma opção de lazer nas cidades menores, um novo hábito se disseminou no país: comer em fast-foods.

Nesse sentido, reafirma-se que o ato de comer não se relaciona somente à manutenção biológica dos corpos, mas concretiza modos de relação entre as pessoas e o mundo, desenhando suas referências fundamentais no espaço-tempo (CERTEAU, 2000 
[1990]). Sendo assim, cultura e mercado se encontram nos lugares, formando novas ordens técnico-culturais e novos espaços de consumo³.

O alegado "charme" das franquias internacionais tem conquistado os consumidores e os empreendedores brasileiros, como observam Ortigoza e Pintaudi (2002). Para as autoras, esse "gosto global" faz com que muitos investidores nacionais se interessem por franquias estrangeiras, ao mesmo tempo em que as empresas nacionais incorporam em seus logotipos e produtos algumas feições internacionais para conquistarem o mercado interno. Debateremos esse processo adiante, a partir das tentativas de instalação da rede KFC no Brasil, ao mesmo tempo em que crescem as redes nacionais que mimetizam o processo desenvolvido pela rede estadunidense.

Pode-se afirmar, portanto, que a globalização do gosto reflete a dialética entre a "psicoesfera" e a "tecnoesfera". Segundo Santos (1996), nos espaços globalizados, psicoesfera e tecnoesfera funcionam de modo unitário e indissociável: esta se constitui como o mundo dos objetos e aquela, como a esfera da ação, reino das ideias, ideologias, crenças, hábitos, desejos e paixões.

Nesse sentido, é possível afirmar que a psicoesfera, como a esfera dos desejos, muitas vezes antecede a chegada da esfera técnica correspondente. Como afirma Ribeiro (1991, p. 48), "essa psicoesfera produz a busca social da técnica e a adequação comportamental à interação moderna entre tecnologia e valores sociais". Por este motivo, o desejo de consumo do frango frito no balde produzido pela rede mundial KFC tem relação dialética com a presença de diversos estabelecimentos nacionais e locais que comercializam este produto no Brasil, de maneira geral, e em Belo Horizonte (MC), especificamente; assunto que será tratado a seguir.

\section{O “frango frito no balde" no Brasil: da padronização global à "tropicalização"}

Defendemos que, ao trazer para o debate as categorias psicoesfera e tecnoesfera, pode-se compreender como cada arranjo territorial é único, uma vez que o impacto modernizador, embora se generalize, é seletivo nos âmbitos nacional, regional e local. No

\footnotetext{
${ }^{3}$ É importante salientar que a discussão aqui trazida é sobre o consumo enquanto uma etapa do processo produtivo da mercadoria. Espera-se, na continuidade da pesquisa, desenvolver análises mais próximas dos consumidores enquanto agentes, incorporando outros elementos fundamentais para a compreensão das mudanças nos hábitos alimentares.
} 
entanto, essa racionalidade encontra resistências no meio ambiente construído, na diversidade das classes sociais, nas diferenças de renda e nos modelos culturais de cada lugar. Santos (1994) denominou esse processo de "flexibilidade tropical", visando destacar os processos de adaptação e criação das massas em face às suas condições objetivas de existências. Nas palavras do autor,

nas grandes cidades, sobretudo no Terceiro Mundo, a precariedade da existência de uma parcela importante (às vezes a maioria) da população não exclui a produção de necessidades, calcadas no consumo das classes mais abastadas. Como resposta, uma divisão do trabalho imitativa, talvez caricatural, encontra as razões para se instalar e se reproduzir. (SANTOS, 1996, p. 259)

Pode-se observar um processo de "tropicalização" nos primeiros restaurantes a oferecer em seu cardápio o frango frito no balde no Brasil: o Chicken-In, inaugurado em 1967 em Campinas (SP), seguido pelo Jet-Chicken, em 1988, no município de Londrina (PR). Logo, o Chicken-In iniciou a venda de frango frito no balde no formato fast-food antes mesmo da primeira tentativa de instalação da KFC no país, em 1978 (Quadro 01). Esta franquia foi fundada por dois americanos residentes em Campinas (SP), que alegam terem se inspirado na loja Chicken-in-the-Basket, um estabelecimento estadunidense especializado em frango frito no balde, assim como a KFC. Em 1968, seus fundadores abriram nova loja no estado do Paraná e, em seguida, iniciaram a abertura de franquias pelo Brasil ${ }^{4}$.

De forma semelhante às estratégias de marketing da KFC, o Chicken-In apresenta ao consumidor como diferenciais de seus produtos os temperos e os ingredientes utilizados no preparo dos alimentos e o fato de possuírem uma receita própria. O sucesso desta rede no Brasil, ainda segundo o site da empresa, deve-se à sua especialização em pratos à base de frango e não, necessariamente, ao frango frito no balde. Seus produtos principais são o frango frito crocante e a polenta frita, acompanhados por porções de batatas fritas, mandioca e purê de batata. Desde a sua fundação, o Chicken-In oferece todas as refeições do dia: almoço, lanche, happy-hour e jantar. Em 2018, a franquia contava com 12 unidades no Brasil e, atualmente, possui 16 lojas, atende mais de 70 mil pessoas por mês e contabiliza mais de 5

${ }^{4}$ Disponível em: http://franquiachickenin.com.br. Acesso em 10 jul. 2019. 
milhões de pratos vendidos. Está presente nos estados de São Paulo, Santa Catarina, Rio Grande do Sul, Rio de Janeiro, Minas Gerais, Acre e Distrito Federal ${ }^{5}$.

Neste contexto, e a respeito das duas tentativas de implantação frustradas da KFC no Brasil entre as décadas de 1970 e 1990, Fontoura (2013, p. 2) assim expõe: "entre as razões que explicam as dificuldades da KFC está, certamente, o produto que ela comercializa, o frango frito. Acontece que outras redes que vendem frango frito, como a Jet Chicken e a Chicken-In, vão bem. O que há de diferente entre elas e a KFC?".

Uma de nossas hipóteses para os fracassos desta rede mundial entre as décadas de 1970 e 1990 no Brasil está na ausência de talheres nos restaurantes KFC e na resistência em comer frango frito e gorduroso com as mãos. Historicamente, na cultura alimentar da sociedade brasileira, a ausência de talheres à mesa se relaciona à pobreza e, por isso, não é admitida nas refeições, como relatado por Auguste de Saint-Hilaire em sua passagem pelas províncias do Rio de Janeiro e de Minas Gerais, em 1817:

os indivíduos de mais baixa categoria, tais como os condutores de bois e de burros, são os únicos que amassam e comem com os dedos a farinha e o feijão-preto. É necessário, aliás, que um homem com casa própria seja muito pobre para não possuir alguns talheres de prata; mas esses talheres são, geralmente, de extrema pequenez. (SAINT-HILAIRE, apud CASCUDO, 2013 [1977], p. 209)

Esse hábito alimentar permanece enraizado na cultura brasileira até a atualidade, o que justifica a resistência à forma de consumo de frango frito no balde, tal como proposto pela $\mathrm{KFC}$, em espaços públicos, mesmo que seja um hábito comum na esfera domiciliar. Sendo assim, concorda-se com Fontoura (2013), quando afirma que o frango frito no balde não fazia parte dos hábitos alimentares dos brasileiros, fato que só foi apreendido pela KFC na década de 2000, quando realizou diversas adaptações em seu cardápio e em seu modus operandi e, finalmente, conseguiu se instalar no Brasil. A Chicken-In, ao contrário, já nasceu adaptada ao gosto brasileiro e à cultura de sua população, por isso foi mais bem-sucedida desde a sua inauguração, em 1967.

Nota-se, portanto, que a tropicalização se impôs de maneira concreta, impedindo uma homogeneização total dos hábitos alimentares, elemento fundamental da estratégia da rede global KFC. Igualmente, pode-se falar em uma flexibilidade tropical na medida em

${ }^{5}$ Disponível em: http://franquiachickenin.com.br. Acesso em 10 jul. 2019. 
que há hoje no Brasil diversas lojas e redes que comercializam o produto "frango frito no balde" (Quadro 01) cujas estratégias são fundamentadas em adaptações que partem dos hábitos alimentares brasileiros.

Embora a maioria delas mimetize o cardápio da KFC, oferecem, ainda, molhos especiais, sanduíches e sobremesas e possuem estratégias de marketing, formatos de lojas, cardápios, preços e embalagens distintas entre si e em relação à própria KFC. Essa adaptação, reiteramos, não é apenas uma garantia contra processos por uso não autorizado de direitos autorais e de marca, mas o reflexo dos artifícios de ajuste que consideram os hábitos alimentares nacionais como fundamentais na definição da ação estratégica dessas redes de alimentação rápida.

Em Belo Horizonte, recorte geográfico da pesquisa, mapeamos 20 estabelecimentos especializados em fornecer baldes de frango frito, localizados nas diversas regiões do município, sobretudo, fora da região Centro-Sul, a mais rica da cidade ${ }^{6}$. Entre eles, a semelhança com a KFC é evidente, ao mesmo tempo que as soluções tecnológicas adaptativas também são marcantes.

Além do frango frito, todos esses restaurantes servem refeições completas, saladas, porções e sobremesas. Este é o principal elemento que distingue as redes adaptadas em relação ao cardápio tradicional da KFC. Afinal, é comum que uma refeição completa, no Brasil, inclua esses itens, além do frango frito, por exemplo, que seria considerado um complemento, ou uma "mistura", em uma das formas mais comuns com as quais as carnes são nomeadas nas refeições.

Os baldes de frango também são bastante diferentes: alguns estabelecimentos buscam uma padronização das embalagens semelhante à da KFC, como é o caso das redes FranCO! Fried Chicken, Lug's Franchising, Frango Americano Brasil, Dot Chicken e Frango Texano, enquanto outros fornecem recipientes de plástico com tampa, o que permite a sua reutilização pelos clientes, que podem, assim, levá-los para casa. O processo de adaptação dessas redes que mimetizam o KFC expande-se, de certa maneira, na continuação da sua adaptação pelos consumidores.

Destaca-se, em 2018, na capital mineira, a presença de cinco lojas da franquia nacional Frango Americano Brasil, sediada em Curitiba (PR); dois estabelecimentos da

\footnotetext{
${ }^{6} \mathrm{O}$ levantamento das redes tem sido feito de forma sistemática a partir das ferramentas dos motores de pesquisa na Internet e redes sociais virtuais, incluindo anúncios e notícias.
} 
franquia regional Dot Chicken, cujas sedes encontram-se em Belo Horizonte; duas unidades da franquia regional FranCo! Fried Chicken; e dois estabelecimentos da franquia internacionalizada Lug's Franchising, que tem sede no estado de São Paulo e franquias por todo o Brasil e em Bogotá, na Colômbia. Estas franquias foram implementadas na capital mineira em 2012, 2013, 2014 e 2015, respectivamente (Quadro 01).

Neste contexto, a diferença entre os agentes dos "circuitos superior e inferior" da economia urbana, conforme Santos (1979), faz-se presente. Enquanto os agentes do circuito superior são padronizados (redes globais de fast-food, como a KFC), os agentes do chamado circuito inferior ${ }^{7}$ dispõem de um considerável potencial de criação apoiado nas condições e limitações dadas pelo local circunscrito de ação. Entre essas formas mais simples e mais sofisticadas, as franquias brasileiras nacionais e internacionalizadas apoiam-se em formas intermediárias de tecnologia e padronização e têm cardápios, embalagens, logotipos e mascotes, como a KFC. Em contrapartida, ainda que se observe uma inspiração ou cópia desta rede mundial, as franquias regionais belo-horizontinas e os demais restaurantes locais têm propostas e práticas diferentes.

Com base nessa relação entre globalização do gosto em tempos e espaços distintos, recupera-se a proposta de Santos (2004 [1978]), para quem a análise do espaço não pode ser feita sem se considerar a existência de um tempo concreto, dividido em seções dotadas de características particulares e que mantêm certo equilíbrio, certas relações. Sendo assim, é possível identificar sistemas temporais, do tempo como sucessão, que permitem uma periodização que fornecerá instrumentos para entender a geografia da rede mundial KFC e seu uso do território belo-horizontino, por meio da implantação de suas franquias na capital mineira. Ao mesmo tempo, revela-se a diversidade de outros estabelecimentos cujo produto principal de venda é o frango frito no balde, como se verá mais detalhadamente a seguir.

\footnotetext{
${ }^{7}$ Segundo Milton Santos, "a diferença fundamental entre as atividades do circuito inferior e as do circuito superior está baseada nas diferenças de tecnologia e de organização. O circuito superior utiliza uma tecnologia importada e de alto nível, uma tecnologia 'capital intensivo', enquanto no circuito inferior a tecnologia é 'trabalho intensivo' e frequentemente local ou localmente adaptada ou recriada" (SANTOS, 1979, p. 43.
} 


\section{Uma proposta de periodização do gosto e das redes de fast-food com "frango frito no balde" no Brasil e em Belo Horizonte (MG)}

A ideia de espaço é indissociável da noção de sistemas de tempo, uma vez que a cada momento da história, a ação de diversas variáveis depende das condições do correspondente sistema temporal ao qual estão vinculadas (SANTOS, 1981). Sendo assim,

a reconstrução dos sucessivos sistemas temporais e dos sistemas espaciais sucessivos é um dado fundamental quando se busca uma explicação para as situações atuais. E isso implica uma identificação exata das periodizações em diferentes níveis ou escalas, assim como o isolamento (com fins metodológicos) dos fatores dinâmicos próprios a cada período e a cada nível ou escala. (SANTOS, 2004 [1978], p. 255)

É possível dizer, então, que, em escala mundial, cada sistema temporal coincide com um período histórico. Desta forma, a sucessão desses sistemas temporais relativos à implantação da venda do fast-food "frango frito no balde" no Brasil e em Belo Horizonte coincide com a sucessão das modernizações nesses territórios.

Uma coisa, porém, é certa. Como em cada sistema há uma combinação de variáveis em escalas diferentes, mas também de "idades" diferentes, cada sistema transmite elementos cuja datação é diferente. O próprio subespaço receptor é seletivo: nem todas as variáveis "modernas" são acolhidas e as variáveis acolhidas não pertencem todas à mesma geração. (SANTOS, 2004 [1978], p. 257)

Fala-se, assim, em "tempos rápidos" e em "tempos lentos" (SANTOS, 1981; 1991): este, tempo das instituições, das firmas e dos homens hegemonizados, e aquele, tempo das grandes firmas, dos indivíduos e das instituições hegemônicas. No setor da alimentação rápida, há também um tempo rápido, isto é, aquele tempo que corresponde à ação normatizada e padronizada, em escala multinacional, de algumas corporações, como a KFC. As redes globais de alimentação rápida agem, também em tempos rápidos, empiricamente exercidos pela sua capacidade de coordenação centralizada de milhares de estabelecimentos espalhados pelo planeta.

Analiticamente, seria equivocado, portanto, igualar esta corporação global que articula o funcionamento de um espaço-tempo global, com capacidade de modificação dos 
ritmos dos locais onde se insere, com outras redes menores cuja ação é regional, nacional ou mesmo parcialmente internacionalizada. Há, ainda, um terceiro nível analítico, que comportaria aquelas empresas que estão muito próximas e limitadas aos tempos dos lugares onde estão instaladas, sendo, assim, empresas locais ou regionais. Estas compartilham e se adaptam aos ritmos cotidianos dos quais elas mesmas surgiram.

Nesse sentido, alguns espaços podem ceder lugar, completa ou parcialmente, a esta modernização, ao passo que outros podem a ela resistir; alguns elementos podem desaparecer e outros, completamente novos, se estabelecer em determinado território. "O espaço, considerado como um mosaico de elementos de diferentes eras sintetiza, de um lado, a evolução do espaço e explica situações que se apresentam na atualidade" (SANTOS, 1981, p. 2).

O autor elucida ainda que a escolha de períodos, ou de sistemas de modernização, para uma periodização histórica não é pré-determinada, mas deve ser tomada da realidade exterior e obedecer aos objetivos do pesquisador. Isto posto, o objetivo da periodização que ora se expõe é apresentar a sucessão de eventos relacionados à implantação de restaurantes de fast-food especializados em venda de frango frito no balde no Brasil e em Belo Horizonte (MG). Antes de ser definitiva, a proposta é um convite a pensar as sucessões e as coexistências espaço-temporais de agentes sociais distintos, representando o estágio atual da pesquisa, podendo ser complementada com outros eventos.

Entendem-se os eventos como vetores das possibilidades existentes numa formação socioespacial, como os acontecimentos que mudam as coisas, transformam objetos, dandoIhes novas características. Desta forma, "é através do evento que podemos rever a constituição atual de cada lugar e a evolução conjunta dos diversos lugares, um resultado da mudança paralela da sociedade e do espaço" (SANTOS, 1996, p.101).

Sendo assim, identificam-se quatro eventos, que delimitam períodos coerentes na periodização proposta, a saber (Quadro 01):

1) KFC: criação, abertura e fechamento de unidades (mundo e Brasil).

2) Brasil: surgimento de redes concorrentes de frango frito no balde.

3) Belo Horizonte (MG): abertura de unidades de redes de frango frito no balde.

4) Belo Horizonte (MC): abertura de unidades da KFC. 


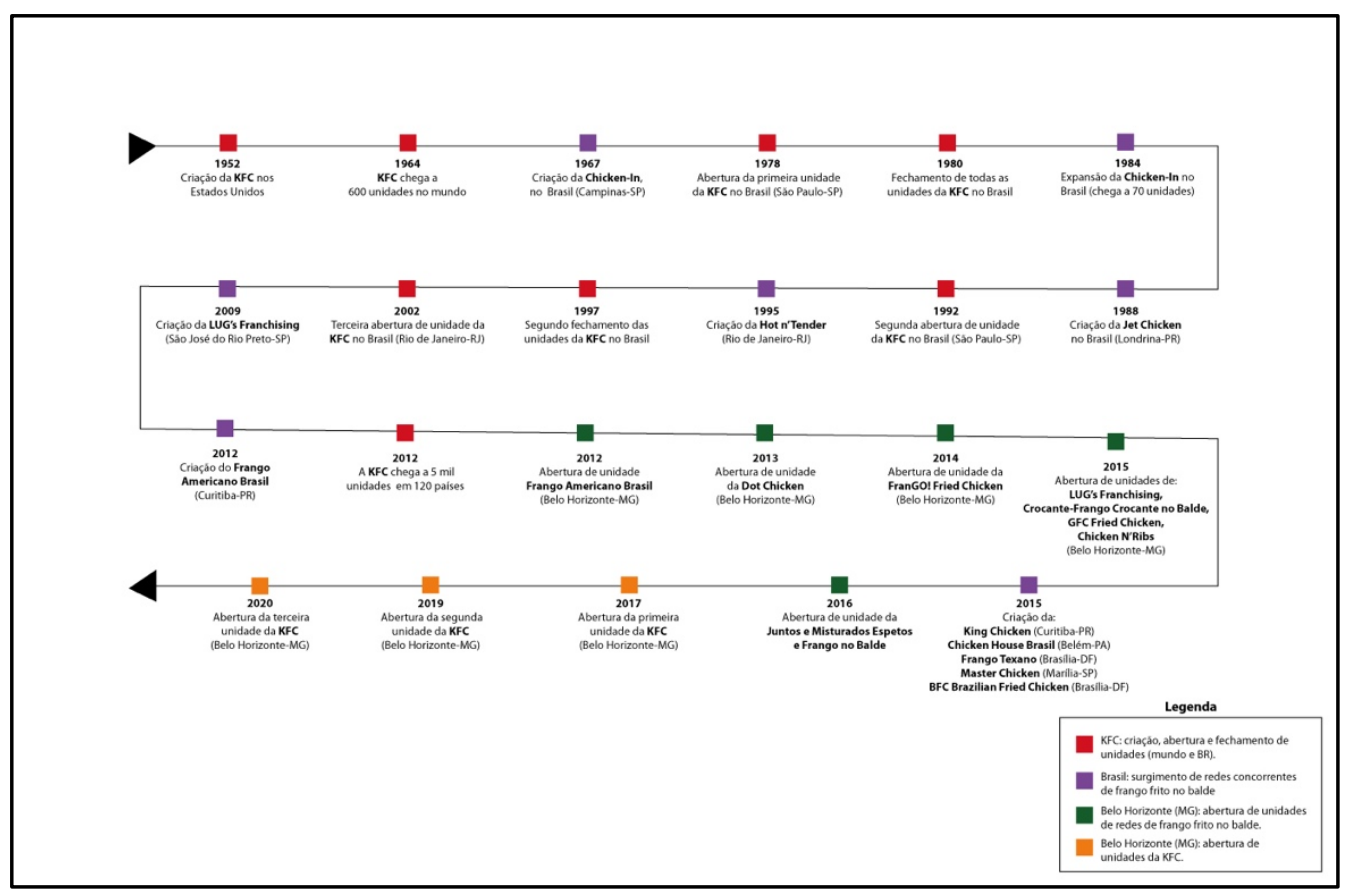

Quadro 1: Periodização da difusão das redes de fast-food de "frango frito no balde" no Brasil, com destaque para Belo Horizonte. Fonte: autoria própria, com base em sites, levantamento bibliográfico, notícias e entrevistas

A partir desses eventos, é possível conceber quatro períodos de uma certa geografia da mudança dos hábitos alimentares vinculados ao consumo de frango frito no balde no Brasil e a importância, no país, das redes de alimentação rápida. O primeiro deles, que se inicia em 1952, corresponde à criação da KFC, nos Estados Unidos, e sua expansão por este país e pelo mundo. Em cerca de dez anos, esta rede de fast-food foi implantada em todo o território estadunidense -600 unidades abertas - e se tornou a mais conhecida marca do país.

Assim, iniciaram-se diversas mudanças estruturais nos hábitos alimentares dos consumidores estadunidenses, que surgem no bojo da aceleração do processo de urbanização daquele país e da construção de infraestruturas territoriais (rodovias, especialmente) que passam a marcar as paisagens. Mudanças nas relações econômicas e nos deslocamentos da força de trabalho, pela banalização do automóvel, conduzem a mudanças nas dietas: alimentar-se fora de casa consolida-se como uma prática corriqueira, como destaca Schlosser (2001). A criação e a expansão geográfica de redes de fast-food, incluindo a KFC, não apenas surgem destas mudanças, mas são também agentes possibilitadores e aceleradores delas. Criaram-se, concomitantemente, a tecnoesfera e a psicoesfera desses hábitos alimentares, que se espraiariam para outros países. 
O segundo período é marcado pelo surgimento de redes concorrentes de frango frito no balde no Brasil, ou seja, pela precedência da psicoesfera sobre a tecnoesfera, a partir da criação do primeiro restaurante brasileiro especializado em frango frito no balde, o ChickenIn, em 1967 no município de Campinas (SP). Nesse sentido, o desejo do consumo se instala no Brasil antes da própria técnica de produção, ou seja, a ordem social criada nos Estados Unidos exerceu maior influência sobre a sociedade e, a partir daí, notou-se expansão da Chichen-In pelo território brasileiro e a criação de outras duas redes de fast-food nacionais até o final da década de 1990: a Jet Chicken, em Londrina (PR), e a Hot n'Tender, no Rio de Janeiro (RJ).

Em contrapartida, a rede KFC registrou, neste período, duas tentativas frustradas de implantação de suas lojas no Brasil: no fim da década de 1970 e no fim da década de 1990, em plena fase de expansão dos restaurantes brasileiros. Essa rede mundial chegou ao Brasil em 1978 com o mesmo formato padrão de sua matriz estadunidense e encontrou resistências na cultura alimentar da sociedade brasileira, ao contrário das versões nacionais, que, ainda que tenham se inspirado na KFC, nasceram adaptadas ao gosto brasileiro.

Em 2003, a KFC instalou-se pela terceira vez no Brasil e, a partir de então, coexiste com redes de franquias nacionais especializadas em frango frito no balde. É preciso destacar o elevado número de redes de restaurantes brasileiros com essa especialidade criados do fim dos anos 2000 até 2015, ou seja, em um momento mais destacado da própria globalização do território nacional. Todas elas configuram-se como franquias e localizam-se em todo o território nacional, enquanto uma delas, a Lug's Franchising, possui franqueados no exterior, com lojas em Bogotá, na Colômbia. Portanto, observa-se, neste período, um segundo movimento, isto é, de internacionalização das redes nacionais.

O terceiro período corresponde à abertura de unidades de redes de frango frito no balde em Belo Horizonte (MG) e tem como evento delimitador a inauguração da primeira franquia da rede Frango Americano Brasil na capital mineira no ano de 2012. Assim como aconteceu em âmbito nacional, a psicoesfera antecedeu a tecnoesfera no território belohorizontino e, devido à escala de análise, observa-se na capital mineira relevante número de restaurantes do circuito inferior da economia, especializados na venda de frango frito no balde, que têm na adaptação sua forma de resistência e continuidade. Estes criaram uma expressiva heterogeneidade de formas e fluxos nesse território e se constituem, empiricamente, em formas de flexibilidade tropical local e/ou regional. 
É preciso ressaltar que o desejo de consumo em Belo Horizonte foi reforçado pela préexistência da KFC em nível mundial, mas, também, pela presença das redes brasileiras de fast-food no país, sobretudo, no eixo Rio-São Paulo, ao longo de 45 anos. Neste sentido, de 2012 a 2015, foram várias e diversas as lojas de franquias nacionais especializadas em frango frito no balde inauguradas na capital mineira. Destaca-se, ainda, a criação de duas franquias regionais belo-horizontinas - a Dot Chicken, em 2013, e a FranCO! Fried Chicken, em 2014-, além de vários restaurantes menores cujas soluções criativas frente à ausência de técnica e adaptações à cultura local são ainda mais evidentes.

O quarto período é marcado pela abertura de unidades da KFC em Belo Horizonte, ou seja, pela chegada da tecnoesfera a partir da inauguração do restaurante KFC no Shopping Diamond Mall, a primeira unidade desta franquia fora do eixo Rio-São Paulo. A escolha por Belo Horizonte, uma das principiais e mais ricas capitais do país, marca o que pode vir a ser um período de interiorização da rede estadunidense em território brasileiro. A escolha pelo Shopping Diamond Mall, com público de rendas mais altas ${ }^{8}$ e localizado em uma zona nobre da região Centro-Sul da cidade, evidencia que a chegada a Belo Horizonte levou em consideração um específico recorte de consumidores, por mais que, originalmente, a rede tenha surgido para suprir de forma barata a dieta alimentar das classes trabalhadoras mais baixas nos Estados Unidos.

Posteriormente, em 2019, foi inaugurada a segunda unidade da KFC em Belo Horizonte, desta vez, em um shopping mais periférico e popular, o Minas Shopping. Localizado na região Nordeste da capital, este centro de compras situa-se ao lado de uma estação do metrô e do BRT/MOVE (Estação Minas Shopping) e, portanto, tem como público

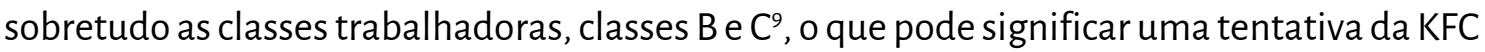
de ampliar seu mercado consumidor em Belo Horizonte, atingindo as classes mais populares.

Em março de 2020 inaugurou-se a terceira unidade da KFC, desta vez no Boulevard Shopping, região Leste da capital. À semelhança do Minas Shopping, esse centro de compras se localiza nas proximidades de uma estação de metrô (Estação Santa Efigênia), entretanto,

\footnotetext{
${ }^{8}$ Segundo o site da Associação Brasileira de Shoppings Centers (Abrasce), 91\% do público do Shopping Diamond Mall pertence às classes A e B. Disponível em: https://abrasce.com.br/shopping/minas-shopping. Acesso em 16 jun. 2020.

${ }^{9}$ Segundo o site da Associação Brasileira de Shoppings Centers (Abrasce), 87\% do público do Minas Shopping pertence às classes B e C. Disponível em: https://abrasce.com.br/shopping/minas-shopping. Acesso em 16 jun. 2020.
} 
tem como público principal as pessoas das classes $A$ e $\mathrm{B}^{10}$, com rendas mais altas, se comparadas ao público do Minas Shopping. Desta forma, assim como aconteceu em âmbito nacional, a KFC-BH passou a coexistir com outros 20 restaurantes especializados em venda de frango frito no balde, inaugurados a partir de 2012 no território belo-horizontino. Os três restaurantes estão em regiões distintas da cidade, mas todos são localizados dentro de shopping centers, o que mostra uma particularidade da estratégia do uso do território belohorizontino pela KFC em relação a São Paulo e Rio de Janeiro, que apresentam também unidades instaladas em vias públicas.

Por fim, afirma-se que estes períodos elencados correspondem a sequências de eventos que significaram importantes mudanças dentro do contexto das relações socioculturais e espaciais que a rede mundial KFC fomentou por sua simples existência enquanto cadeia de fast-food global no Brasil e em Belo Horizonte (MG). Por meio deles, foi possível apontar caminhos para o entendimento das lógicas externas (globais) e das lógicas internas (nacionais, regionais e locais) a elas subordinadas.

\section{Homogeneização do gosto e diferenciação espacial: algumas considerações parciais de uma pesquisa em curso}

A periodização do fast-food "frango frito no balde" corresponde a sequências de eventos que significaram importantes mudanças dentro do contexto das relações socioculturais e espaciais que a rede mundial KFC fomentou enquanto cadeia de fast-food global. A dialética entre psicoesfera e tecnoesfera manifesta-se, concretamente, no fato de que o hábito de comer, com as mãos, frango frito no balde chega antes, por meio das redes nacionais ou locais (Lug's Franchising, FranCo! Fried Chicken e Dot Chicken). Dessa maneira, quando a KFC instala sua primeira unidade em Belo Horizonte, ou seja, quando a materialidade (tecnoesfera) se associa à cidade, ela se beneficia de uma condição prévia, a psicoesfera, difundida pelos seus concorrentes, mas, também, por grandes campanhas de publicidade e marketing, nacionais e locais.

Assim como aconteceu em âmbito nacional, a psicoesfera antecedeu a tecnoesfera no território belo-horizontino, isto é, o hábito chegou antes da rede que o criou e, devido à

\footnotetext{
${ }^{10}$ Segundo o site da Associação Brasileira de Shoppings Centers (Abrasce), $72 \%$ do público do Minas Shopping pertence às classes A e B. Disponível em: https://abrasce.com.br/shopping/boulevard-shopping-belohorizonte. Acesso em 16 jun. 2020.
} 
escala de análise, observa-se na capital mineira relevante número de restaurantes do circuito inferior da economia especializados na venda de "frango frito no balde", criando formas híbridas entre a reprodução dos padrões KFC e adaptações diversas: alguns restaurantes comercializam cortes de frango empanados com queijo parmesão, queijo Minas, chilli apimentado e bacon (Dot Chicken, Frango Americano Brasil e Cocotas Chicken, por exemplo), e outros, cortes de frango empanados "em estilo americano, mas com tempero mineiro" (Uai Fried Chicken $)^{11}$.

A diversidade de refeições oferecidas por esses estabelecimentos também é relevante: balde de risoto, coração e moela de frango "empanados e preparados ao tempero americano" (Frango Americano Brasil); meio da asa e coxinha da asa empanados e servidos em baldes (Cocotas Chicken, Uai Fried Chicken, Juntos e Misturados Espetos e Frango no Balde). Nota-se, portanto, que há várias soluções criativas, inspiradas no carro-chefe da KFC, mas suficientemente adequadas ao público desses estabelecimentos locais.

A ideia de se fazer o meio da asa e a coxa da asa de frango empanados, por exemplo, sugere uma mistura entre o frango empanado da KFC e o tradicional frango a passarinho servido nos bares de Belo Horizonte. Nessa cidade, conhecida popularmente como a "Capital Mundial dos Bares", o "frango frito no balde" é vendido, sobretudo, em estabelecimentos que têm esse produto como um dos acompanhamentos, ou "tira-gosto", da cerveja.

Assim, sua publicidade está atrelada, principalmente, a happy-hours e eventos como os campeonatos de futebol transmitidos pela televisão. Logo, os restaurantes que comercializam o "frango frito no balde" almejam que a permanência dos clientes no estabelecimento seja maior do que em uma rede de fast-food. Diferem-se, assim, das propostas de refeições rápidas da KFC e das franquias brasileiras de fast-food internacionalizadas, instaladas, sobretudo, em shoppings centers, em um formato de loja compacto, mas de grande produtividade e rápida circulação de consumidores. Até o momento, aliás, os shoppings foram os locais escolhidos pela estratégia de instalação da KFC em Belo Horizonte.

As soluções para o "balde de frango" também são diversas. A Dot Chicken, por exemplo, sediada em Belo Horizonte, tem suas embalagens produzidas no estado de São Paulo, de maneira muito semelhante aos baldes utilizados pela KFC. Outros restaurantes, como o Cocotas Chicken, o Frango Americano Brasil e o Uai Fried Chicken, por exemplo, têm

\footnotetext{
${ }^{11}$ Disponível em: https://www.facebook.com/uaifrangofritobh. Acesso em 12 jun. 2020.
} 
baldes de plástico retornáveis, que são levados pelos clientes e reutilizados para diversas funções em suas casas. Assim, esses restaurantes do circuito inferior da economia criaram uma expressiva heterogeneidade de formas. O território, que é o sinônimo geográfico para a cultura, impõe uma resistência e, dessa maneira, é possível afirmar que o circuito inferior desenvolveu soluções criativas e mais bem contextualizadas à cultura brasileira, revelando, empiricamente, manifestações de flexibilidade tropical.

Dialeticamente, assim como outras redes de fast-food americanas, a KFC influenciou, por meio da informação difundida mundialmente, a criação de um novo modelo de consumo em Belo Horizonte, mesmo antes de sua presença concreta. Nesse sentido, a precedência da psicoesfera em relação à tecnoesfera revela a ação de forças sociais hegemônicas que geram uma relação dialética e indissociável entre o circuito superior e o circuito inferior da economia nesse território.

Faz-se ainda necessário, com o avançar dessa pesquisa ainda em curso, aprimorar a tipologia para compreender as diferentes formas constitutivas dessas empresas, considerando, especialmente a capitalização (alta ou baixa), as formas de organização (burocráticas ou rudimentares), as tecnologias utilizadas (avançadas ou simples) e o uso da informação (conhecimento do território e do mercado consumidor). Isso permitiria, acreditase, compreender as formas adaptativas dos pequenos estabelecimentos, inegavelmente pertencentes a um circuito inferior local, assim como a rede nacional já internacionalizada (Lug's Franchising), todavia em estágio intermediário em relação ao que existe de mais moderno no setor de alimentação rápida.

Constata-se, finalmente, que há na capital mineira relevante número de restaurantes do circuito inferior da economia (Frango Americano Brasil, Dot Chicken, FranCO! Fried Chicken, Crocante-Frango Crocante no Balde, GFC Fried Chicken, Chicken N'Ribs, Juntos e Misturados Espetos, Frango no Balde, dentre outros), especializados nas formas adaptadas de venda de frango frito no balde, e atendendo a um consumo sobretudo das classes mais populares.

Contudo, mesmo nas suas formas localmente gestadas como pequenos comércios, subsiste, como processo alimentar contemporâneo, um debate societário sobre o qual todas as áreas e saberes (práticos, técnicos ou científicos) devem ser chamadas a contribuir: qual o sentido da alimentação? Os alimentos, como nos lembra Morel et al. (2016), ultrapassam a necessidade vital humana e sua escolha é pautada por questões sociais e culturais. Assim, 
hábitos alimentares estrangeiros dividem espaço com hábitos historicamente perpetuados localmente, criando ou desfazendo identidades alimentares ao longo do tempo. De nossa parte, gostaríamos de retomar a questão levantada por Josué de Castro (1961 [1946]) em sua pioneira Geografia da fome, de que o processo de emancipação humano passa também por uma consciência sobre o alimentar-se.

\section{Referências}

CASCUDO, Luís da Câmara. Antologia da alimentação no Brasil. São Paulo: Clobal, 2013 [1977].

CASTRO, Josué de. Geografia da fome. O dilema brasileiro: pão ou aço. São Paulo: Editora Brasiliense, 1961 [1946].

CERTEAU, Michel de. A invenção do cotidiano: morar, cozinhar (v. 2). $3^{\mathrm{a}}$ ed. Petrópolis: Vozes, 2000 [1990].

FISCHLER, Claude. A 'McDonaldização' dos costumes. In: FLANDRIN, Jean-Louis; MONTANARI, Massimo. História da alimentação. São Paulo: Estação Liberdade, 2015 [1996].

FONTOURA, Marília. Marcas fortes, negócios nem tanto. Revista Exame, 22 jul. 2013.

Disponível em: https://exame.abril.com.br/revista-exame/marcas-fortes-negociosnem-tanto-moo53872. Acesso em 28 abr. 2018.

FUMEY, Giles; RAFFARD, Pierre. Atlas de l'alimentation. Paris: CNRS Éditions, 2018.

LEFEBVRE, Henri. O direito à cidade. São Paulo: Editora Documentos, 1969 [1968] .

LEONARDO, Maria. Antropologia da alimentação. Revista Antropos, v. 3, p. 1-6, dez. 2009. Disponível em:

http://www.revista.antropos.com.br/downloads/dez2009/Artigo\%201\%20\%20Anntropologia\%20da\%20Alimenta\%E7\%E30\%20-\%20Maria/2oLeonardo.pdf. Acesso em 27 abr. 2018.

MOREL, Aline Pereira Sales et al. Novos debates interdisciplinares: antropologia da alimentação e comportamento do consumidor. Diálogos Interdisciplinares, v. 5, n. 1, p. 178-197, 2016. Disponível em:

https://revistas.brazcubas.br/index.php/dialogos/article/view/152. Acesso em 27 abr. 2018. 
ORTIGOZA, Sílvia Aparecida Guarnieri. Alimentação e saúde: as novas relações espaçotempo e suas implicações nos hábitos de consumo de alimentos. RA'ECA, Curitiba, n. 15, p. 83-93, 2008. Disponível em: https://revistas.ufpr.br/raega/article/view/14247. Acesso em 25 mar. 2017.

ORTIGOZA, Sílvia Aparecida Guarnieri; PINTAUDI, Silvana Maria. O tempo e o espaço da alimentação no centro da metrópole paulista. In: GERARDI, Lúcia Helena de O.; MENDES, landara Alves (orgs.). Do natural, do social e de suas interações: visões geográficas. São Paulo: Editora Unesp, 2002.

RIBEIRO, Ana Clara Torres. Matéria e espírito: o poder (des)organizador dos meios de comunicação. In: PIQUET, Rosélia; RIBEIRO, Ana Clara Torres (orgs.). Brasil, território da desigualdade: descaminhos da modernização. Rio de Janeiro: Jorge Zahar Editora/Fundação Universitária José Bonifácio, 1991.

RIBEIRO, Ana Clara Torres. Oriente Negado: cultura, mercado e lugar. Cadernos PPGAU/FAUFBA, v. 3, n. especial, p. 97-107, 2004.

RIBEIRO, Ana Clara Torres. Por uma sociologia do presente: ação, técnica e espaço (v. 3). Rio de Janeiro: Letra Capital, 2013.

SANTOS, Milton. $\mathbf{O}$ espaço dividido: os dois circuitos da economia urbana dos países subdesenvolvidos. Rio de Janeiro: Francisco Alves, 1979.

SANTOS, Milton. Dimensão temporal e sistemas espaciais no terceiro mundo. Anuário IGEOUFRJ, Rio de Janeiro, v. 5, p. 1-15, 1981. Disponível em: http://www.ppegeo.igc.usp.br/index.php/anigeo/article/view/1928. Acesso em 27 abr. 2018.

SANTOS, Milton. O tempo nas cidades. Coleção Documentos, Série Estudos Sobre o Tempo, IEA-USP, n. 2, p. 21-22, 1991.

SANTOS, Milton. Técnica, espaço, tempo: globalização e meio técnico-científicoinformacional. São Paulo: Hucitec, 1994.

SANTOS, Milton. A natureza do espaço. Técnica e tempo. Razão e emoção. São Paulo: Editora Hucitec, 1996.

SANTOS, Milton. Por uma geografia nova: da crítica da geografia a uma geografia crítica. São Paulo: Edusp, 2004 [1978].

SCHLOSSER, Eric. Fast Food Nation: The Dark Side of the All-American Meal. Boston: Houghton Mifflin Company, 2001. 